\title{
Poor outcome of patients with pulmonary adenocarcinoma showing decreased E-cadherin combined with increased S100A4 expression
}

\author{
NORIYUKI MIYAZAKI ${ }^{1}$, YOSHIYUKI ABE ${ }^{1}$, YASUHISA OIDA ${ }^{2}$, HIROSHI SUEMIZU $^{3}$, \\ MASATAKE NISHI $^{1}$, HITOSHI YAMAZAKI ${ }^{1}$, MASAYUKI IWASAKI ${ }^{2}$, HIROSHI INOUE $^{2}$, \\ YOSHITO UEYAMA $^{1,3}$ and MASATO NAKAMURA ${ }^{1,3}$

\begin{abstract}
Departments of ${ }^{1}$ Pathology, and ${ }^{2}$ Surgery, Tokai University School of Medicine, Bohseidai, Isehara, Kanagawa 259-1193;
${ }^{3}$ Central Institute for Experimental Animals, Nogawa 1430, Kawasaki, Kanagawa 216-0003, Japan
\end{abstract}

Received November 30, 2005; Accepted January 20, 2006

\begin{abstract}
A loss or reduced expression of E-cadherin, the main cell-to-cell adhesion molecule, correlates with distant metastasis in various cancers. Recent studies have reported a close correlation between the expression of E-cadherin and that of S100A4, calcium-binding protein. In this study, we investigated the expression of E-cadherin and S100A4 status in relation to the clinicopathological parameters of pulmonary adenocarcinoma. We finely and quantitatively examined the expression of E-cadherin and $\mathrm{S} 100 \mathrm{~A} 4$ using real-time polymerase chain reaction (PCR) in a total of 92 pulmonary adenocarcinomas obtained by surgical resection. All of the pulmonary adenocarcinomas showed significant expression of E-cadherin and S100A4. Real-time PCR showed lower E-cadherin expression in 21 adenocarcinomas, while 71 adenocarcinomas expressed a higher expression of E-cadherin. Of 21 adenocarcinomas with lower-expressing E-cadherin, 12 showed a higher expression of S100A4. These 12 cases significantly showed a poorer prognosis than others $(\mathrm{p}=0.047$, Kaplan-Meier, log-rank test) and significantly showed more frequent venous involvement than others $\left(p=0.042, \chi^{2}\right.$ test). These results suggested that reduced E-cadherin expression combined with higher S100A4 expression is related to a poor prognosis through hematogenous metastasis in pulmonary adenocarcinoma.
\end{abstract}

\section{Introduction}

E-cadherin is the main cell-to-cell adhesion molecule that participates in homophilic, calcium-dependent interactions to

Correspondence to: Dr Masato Nakamura, Department of Pathology, Tokai University School of Medicine, Bohseidai, Isehara, Kanagawa 259-1193, Japan

E-mail: mnakamur@is.icc.u-tokai.ac.jp

Key words: E-cadherin, S100A4, pulmonary adenocarcinoma, prognosis, metastasis form the epithelial adherence junction $(1,2)$. A loss or the reduced expression of E-cadherin is correlated with distant metastasis in various advanced cancers, including lung cancer $(3,4)$. Thus, E-cadherin is assumed to act as a main invasionsuppressor molecule $(5,6)$. Recent studies have reported the close correlations between S100A4 and E-cadherin expression in stomach and gallbladder cancers $(7,8)$.

The S100 family of calcium-binding proteins are involved in a variety of physiological functions, such as cellular proliferation, adhesion and motility (9). S100A4, a small member of the S100 family, formerly known as p9Ka or mts 1, has been characterized as a 'metastasis-related gene' $(10,11)$. The elevated level of S100A4 protein correlated with the metastatic potential of breast neoplasm in rodent models (12-14). The induced expression of S100A4 increased the metastatic potentials in several rodent models of mammary carcinogenesis $(15,16)$. A high incidence of pulmonary metastasis of mammary carcinomas has been observed in S100A4 transgenic mice $(15,17)$. S100A4 overexpression has been associated with a poor prognosis in a variety of human cancers, such as stomach, colon, breast and gallbladder (7,18-20).

In this study, we finely and quantitatively examined the gene expression of E-cadherin and S100A4 by real-time PCR in a total of 92 pulmonary adenocarcinomas obtained by complete surgical resection. We also evaluated the clinical prognosis with long-term observation periods of 5-15 years in the 92 cases with pulmonary adenocarcinoma. We here discuss the relationship between the expression of E-cadherin and S100A4 and clinicopathological features in the 92 cases with pulmonary adenocarcinoma.

\section{Patients and methods}

Patients. Ninety-two pulmonary adenocarcinoma specimens were obtained at surgical resection from October 1989 to November 1999 with the patients' informed consents. All cases underwent complete resection (lobectomy or pneumonectomy and dissection of mediastinal lymph nodes) of pulmonary adenocarcinoma. Tissues were frozen and stored at $-80^{\circ} \mathrm{C}$ until analyses. Surgical specimens were also processed for routine histopathological analysis. The pathological stages 

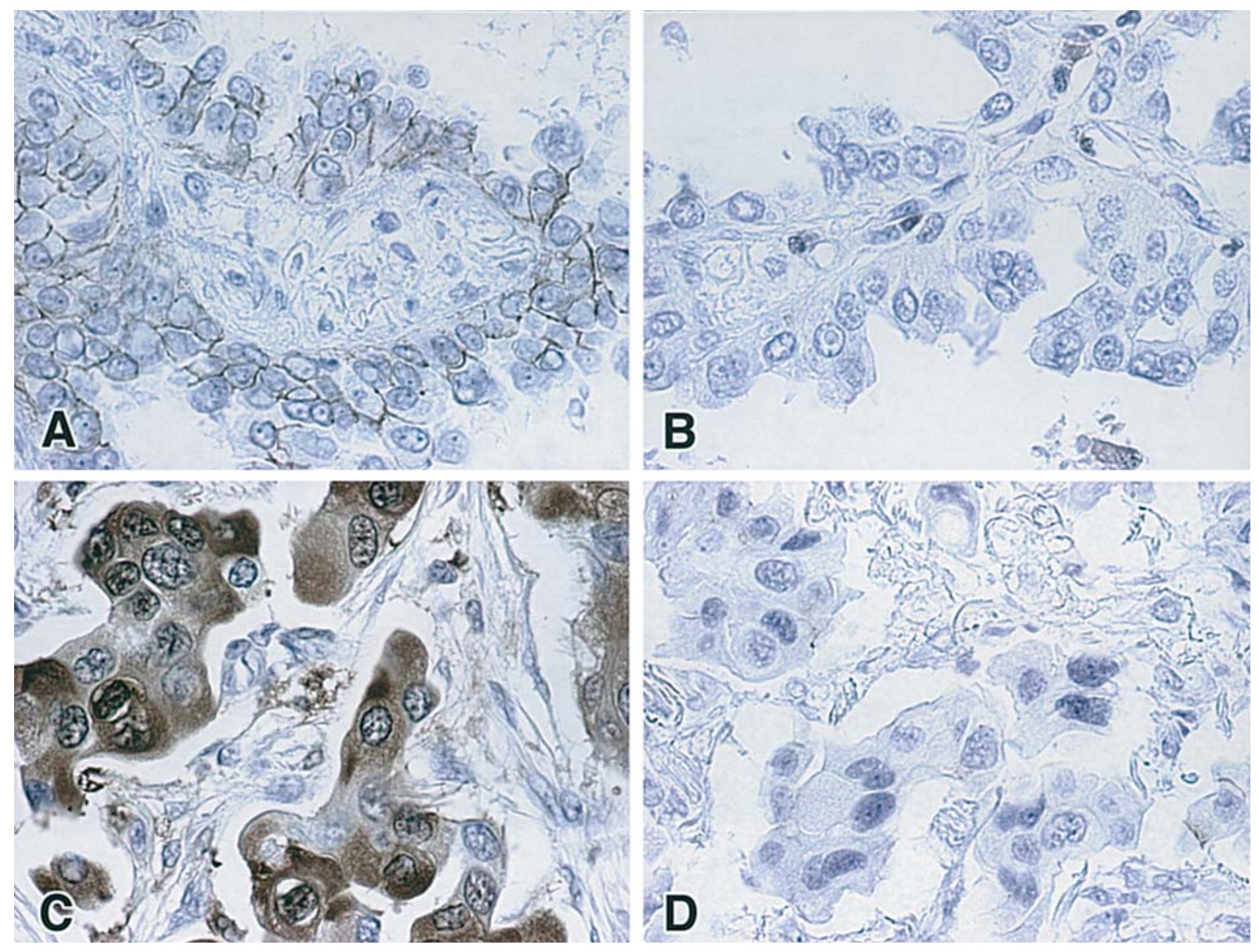

Figure 1. Protein localization of E-cadherin and S100A4. The cancerous nests with well-differentiated papillary features showed E-cadherin expression in the plasma membrane (A) but no apparent S100A4 expression (B). The poorly-differentiated cancerous nests revealed strong S100A4 expression in the cytoplasm and nucleus (C) but no apparent E-cadherin expression (D).

were estimated according to the World Health Organization (WHO) classification (21).

The patients consisted of 48 men and 44 women with a mean age of $63.0 \pm 9.47$ years (mean \pm standard deviation). The pathological stages of the pulmonary adenocarcinoma were as follows: stage I, $52(56.5 \%)$ patients; stage II, 10 (10.9\%) patients; stage III, $30(32.6 \%)$ patients. Tumor status was T1 in 40 patients, T2 in 42, T3 in 7 and T4 in 3. Fifty-four patients had no lymph node metastasis (N0), whereas 38 had regional or mediastinal lymph node metastasis (11 had N1, 26 had N2 and 1 had N3 disease).

Quantitative evaluation of E-cadherin and S100A4. Total cellular RNA was prepared from the frozen specimens by standard acid guanidine isothiocyanate-phenol-chloroform extraction procedures. After heat-denaturation of total RNA specimens $(1 \mu \mathrm{g})$, reverse transcription was performed $[10 \mathrm{mM}$ DTT (Invitrogen Corp., Carlsbad, CA, USA), 0.2 mM dNTPs (Toyobo Co., Osaka, Japan) 100 pmol of Primer, Random PD (N6), (Roche Diagnostics Co., Indianapolis, IN, USA) and 200 units of Superscript ${ }^{\mathrm{TM}}$ II RNase $\mathrm{H}^{-}$Reverse Transcriptase (Invitrogen) at $\left.42^{\circ} \mathrm{C}, 60 \mathrm{~min}\right](22,23)$. Real-time quantitative PCR for E-cadherin and S100A4 mRNA was performed according to the manufacturer's recommendation and our previous reports (24-26). The primers of E-cadherin
(Hs00170423) and S100A4 (Hs00243201) were purchased from TaqMan Gene Expression Assays. We used TaqMan Universal PCR Master Mix (PE Applied Biosystems, Foster City, CA) for the real-time PCR. For the internal controls, $\beta$-actin-probe-primer mixture for $\beta$-actin mRNA was used (human ACTB, 4310881E, PE Applied Biosystems). Real-time PCR assays were run on an ABI PRISM 7000 Sequence Detection System with the following protocol: initial denaturation for $2 \mathrm{~min}$ at $50^{\circ} \mathrm{C}$ and $10 \mathrm{~min}$ at $95^{\circ} \mathrm{C}$, and amplification for 50 cycles of $15 \mathrm{sec}$ at $95^{\circ} \mathrm{C}$ and $60 \mathrm{sec}$ at $60^{\circ} \mathrm{C}$. All of the samples were run in duplicate.

After determining the threshold cycle $\left(\mathrm{C}_{\mathrm{t}}\right)$, which was defined as the PCR cycle number where the fluorescent intensity exceeded the threshold, the amount of E-cadherin and S100A4 mRNA in the sample specimen was calculated from the $\mathrm{C}_{\mathrm{t}}$ of the sample and the RNA standard curve. Then, the relationship between the $C_{t}$ and initial standard copy number was expressed as a logarithmic formula. The obtained copy of E-cadherin and S100A4 was then standardized with the $\beta$-actin mRNA quantity as the endogenous control using the following equation: Result $=\log ($ E-cadherin or S100A4 RNA copy number in surgical samples)/(ß-actin RNA copy number in surgical samples) $\mathrm{x}\left(6.1 \times 10^{9}\right)$.

Gene levels are estimated with standard expression in the control cell lines (defined as 1.00). We used G361 (human 
skin malignant melanoma cell line) as standard for E-cadherin. The human skin malignant melanoma cell line, A375, was used as the standard for the evaluation of the S100A4.

Immunohistochemistry. The formalin-fixed and paraffinembedded tissue samples were processed for immunohistochemistry. The sections were incubated with mouse monoclonal anti-E-cadherin antibodies (Takara, Ootsu Japan) and rabbit polyclonal anti-S100A4 antibodies (Dako, Glostrup, Denmark) at room temperature for $60 \mathrm{~min}$. The E-cadherin immune complex was amplified with the HRP-labeled anti-mouse immunoglobulin (secondary antibody) after antigen retrieval (autoclaved in $1 \mathrm{mM}$ EDTA for $10 \mathrm{~min}$ at $121^{\circ} \mathrm{C}$ ) and the blocking of endogenous peroxidase activity with $0.3 \%$ hydrogen peroxide for $5 \mathrm{~min}$. The S100A4 immune complex was amplified with the HRP-labeled anti-rabbit immunoglobulin (secondary antibody) after antigen retrieval (microwaved in $0.01 \mathrm{M}$ citrate buffer for $20 \mathrm{~min}$ at $95^{\circ} \mathrm{C}$ ) and blocking of endogenous peroxidase activity with $0.3 \%$ hydrogen peroxide for $5 \mathrm{~min}$. The amplified immune products were visualized using a 3,3'-diaminobenzidine tetrahydrochloride (DAB) reaction.

Statistical analysis. The $\chi^{2}$ test was applied for comparisons between group frequencies. Differences in survival between subgroups of patients were compared using the log-rank test, and survival curves were plotted according to the method of Kaplan-Meier. Data are shown as means \pm standard deviation.

\section{Results}

Expression of S100A4 and E-cadherin in pulmonary adenocarcinomas. All of the pulmonary adenocarcinomas showed significant expression of E-cadherin and S100A4 by real-time PCR. The expression levels of E-cadherin in neoplastic tissue varied from 0.600 to $15.369(5.549 \pm 3.243)$. In the 21 extraneoplastic tissues, the expression levels of E-cadherin mRNA varied from 0.822 to $4.559(2.069 \pm 0.891)$. The expression levels of S100A4 in neoplastic tissue varied from 0.027 to $0.730(0.155 \pm 0.117)$. In the 21 extraneoplastic tissues, the expression levels of S100A4 varied from 0.132 to 0.893 $(0.403 \pm 0.187)$. No inverse relation was apparent between E-cadherin and S100A4 expression.

We confirmed the cellular localization of E-cadherin and S100A4 protein by immunohistochemistry. E-cadherin expression was observed in the plasma membrane of tumor cells of adenocarcinoma. The cancerous cells with welldifferentiated papillary features showed E-cadherin expression (Fig. 1A) but no S100A4 expression (Fig. 1B). The poorly differentiated cancerous cells revealed strong S100A4 expression (Fig. 1C) but no E-cadherin expression (Fig. 1D).

Clinicopathological implications of S100A4 and E-cadherin expression. The post-surgical observation period lasted from 0.2 to 149.6 months $(54.3 \pm 41.6$ month). Twenty-one cases were categorized as the lower E-cadherin expressing $(<3.000)$ group of 92 pulmonary adenocarcinoma cases.

There was no significant difference in prognosis between the lower E-cadherin expressing group and the higher Ecadherin expressing group $(\mathrm{p}=0.114$, Kaplan-Meier, log-rank
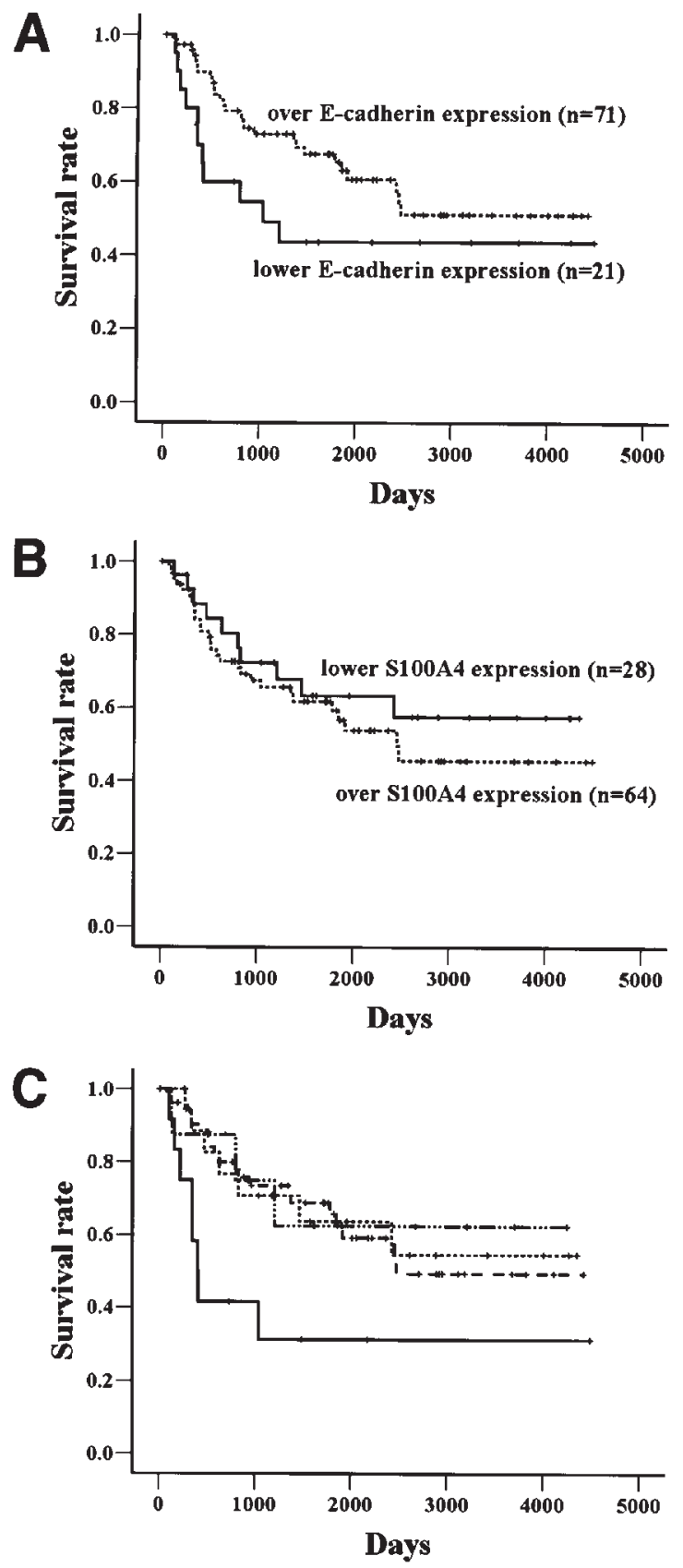

Figure 2. Survival curves of the cases with pulmonary adenocarcinoma. (A) There was no significant difference of prognosis between the 21 cases with lower E-cadherin expression and the other 71 cases ( $\mathrm{p}=0.114$, Kaplan-Meier, log-rank test). (B) There was also no significant difference of prognosis between the 28 cases with lower S100A4 expression and the other 64 cases $(p=0.453$, Kaplan-Meier, log-rank test). (C) Survival curves of four groups subdivided according to the expression status of E-cadherin and S100A4. The cases with lower-expressing E-cadherin and overexpressing S100A4 tumors (continuous line, $\mathrm{n}=12$ ) showed a significantly poorer prognosis than those with tumors of the other three groups; those with lower-expressing E-cadherin and lower-expressing S100A4 (dashed and dotted line, $n=9$ ), overexpressing E-cadherin and lower-expressing S100A4 (dotted line, $n=19$ ), and overexpressing E-cadherin and overexpressing S100A4 (dashed line, $\mathrm{n}=52)(\mathrm{p}=0.047$, Kaplan-Meier, log-rank test).

test) (Fig. 2A). The sixty-four pulmonary adenocarcinomas showed higher levels of S100A4 (>0.1). There was also no significant difference in prognosis between the lower S100A4 expressing group and the higher S100A4 expressing group ( $\mathrm{p}=0.453$, Kaplan-Meier, log-rank test) (Fig. 2B). 
Table I. Gene expression of E-cadherin and S100A4, and venous involvements.

\begin{tabular}{lccc}
\hline & \multicolumn{2}{c}{ Venous involvements } & \\
\cline { 2 - 3 } Gene expression & $(+)(\%)$ & $(-)(\%)$ & p-value \\
\hline E-cadherin/S100A4 & & & $0.042^{\text {a }}$ \\
Higher/higher & $29(31.5)$ & $23(25.0)$ & \\
Higher/lower & $9(9.8)$ & $10(10.9)$ & \\
Lower/higher & $10(10.9)$ & $2(2.2)$ & \\
Lower/lower & $2(2.2)$ & $7(7.6)$ & \\
Total & $50(54.3)$ & $42(45.7)$ &
\end{tabular}

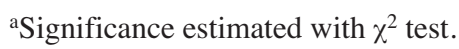

Table II. Gene expression of E-cadherin and S100A4, and metastatic organs.

\begin{tabular}{|c|c|c|c|c|c|c|}
\hline \multirow{2}{*}{$\begin{array}{l}\text { Metastatic } \\
\text { organ }\end{array}$} & \multicolumn{3}{|c|}{$\begin{array}{c}\text { E-cadherin } \\
\text { overexpression }\end{array}$} & \multicolumn{3}{|c|}{$\begin{array}{c}\text { S100A4 } \\
\text { overexpression }\end{array}$} \\
\hline & $(+)$ & $(-)$ & p-value & $(+)$ & $(-)$ & p-value \\
\hline \multicolumn{7}{|l|}{ Total } \\
\hline$(+)$ & 30 & 7 & 0.464 & 29 & 8 & 0.132 \\
\hline$(-)$ & 41 & 14 & & 35 & 20 & \\
\hline
\end{tabular}

Lung

$\begin{array}{lrrrrrr}(+) & 10 & 1 & 0.247 & 9 & 2 & 0.347 \\ (-) & 61 & 20 & & 55 & 26 & \end{array}$

Brain

$\begin{array}{lrrrrrr}(+) & 13 & 3 & 0.669 & 12 & 4 & 0.603 \\ (-) & 58 & 18 & & 52 & 24 & \end{array}$

Bone

$\begin{array}{lrrrrrr}(+) & 11 & 4 & 0.698 & 12 & 3 & 0.337 \\ (-) & 60 & 17 & & 52 & 25 & \end{array}$

Liver

\begin{tabular}{lrrrrrr}
$(+)$ & 1 & 0 & 0.584 & 0 & 1 & 0.128 \\
$(-)$ & 70 & 21 & & 64 & 27 & \\
$\begin{array}{l}\text { Adrenal } \\
\text { gland }\end{array}$ & & & & & & \\
$(+)$ & 0 & 1 & 0.064 & 1 & 0 & 0.506 \\
$(-)$ & 71 & 20 & & 63 & 28 & \\
\hline
\end{tabular}

Twelve of the 21 adenocarcinomas with lower-expressing E-cadherin showed higher expression of S100A4. These lower E-cadherin and higher S100A4 expressing cases significantly showed a poorer prognosis ( $\mathrm{p}=0.047$, Kaplan-Meier, log-rank test) (Fig. 2C). These 12 cases also showed significantly enhanced venous involvement $\left(\mathrm{p}=0.042, \chi^{2}\right.$ test, Table I).
Table III. Univariate analysis of the associations between E-cadherin gene expression and clinicopathological features in pulmonary adenocarcinoma.

\begin{tabular}{lccc}
\hline & \multicolumn{2}{l}{ E-cadherin overexpression } & \\
\cline { 2 - 4 } Variable & $(+)(\%)$ & $(-)(\%)$ & p-value \\
\hline Stage & & & 0.827 \\
I & $41(44.6)$ & $11(12.0)$ & \\
II & $8(8.7)$ & $2(2.2)$ & \\
III & $22(23.9)$ & $8(8.7)$ & \\
T factor & & & \\
T1 & $33(35.9)$ & $7(7.6)$ & \\
T2 & $31(33.7)$ & $11(12.0)$ & \\
T3 & $5(5.4)$ & $2(2.2)$ & \\
T4 & $2(2.2)$ & $1(1.1)$ & \\
N factor & & & \\
N (+) & $28(30.4)$ & $10(10.9)$ & \\
N (-) & $43(46.7)$ & $11(12.0)$ & \\
M factor & & & \\
M0 & $41(44.6)$ & $14(15.2)$ & \\
M1 & $30(32.6)$ & $7(7.6)$ & \\
Total & $71(74.0)$ & $21(26.0)$ & \\
\hline
\end{tabular}

Table IV. Univariate analysis of the associations between S100A4 gene expression and clinicopathological features in pulmonary adenocarcinoma.

\begin{tabular}{|c|c|c|c|}
\hline \multirow[b]{2}{*}{ Variable } & \multicolumn{2}{|c|}{ S100A4 overexpression } & \multirow[b]{2}{*}{ p-value } \\
\hline & $(+)(\%)$ & $(-)(\%)$ & \\
\hline Stage & & & 0.342 \\
\hline I & $33(35.9)$ & 19 (20.7) & \\
\hline II & $8 \quad(8.7)$ & $2(2.2)$ & \\
\hline III & $23(25.0)$ & $7 \quad(7.6)$ & \\
\hline $\mathrm{T}$ factor & & & 0.321 \\
\hline $\mathrm{T} 1$ & $29(31.5)$ & $11(12.0)$ & \\
\hline $\mathrm{T} 2$ & $26(28.3)$ & $16(17.4)$ & \\
\hline T3 & $6 \quad(6.5)$ & 1 (1.1) & \\
\hline $\mathrm{T} 4$ & $3(3.3)$ & $0 \quad(0)$ & \\
\hline $\mathrm{N}$ factor & & & 0.238 \\
\hline $\mathrm{N}(+)$ & $29(31.5)$ & $9 \quad(9.8)$ & \\
\hline N (-) & $35(38.0)$ & $19(20.7)$ & \\
\hline M factor & & & 0.132 \\
\hline M0 & $29(31.5)$ & $8 \quad(8.7)$ & \\
\hline M1 & $35(38.0)$ & $20(21.7)$ & \\
\hline Total & $64(69.6)$ & $28(30.4)$ & \\
\hline
\end{tabular}


However, no significant correlation was noted between metastatic organs and gene expression patterns of E-cadherin or S100A4 (Table II). Univariate analysis showed no significant correlations between E-cadherin or S100A4 expression levels and clinicopathological features in pulmonary adenocarcinoma (Tables III and IV).

\section{Discussion}

We finely and quantitatively examined the gene expression of E-cadherin and S100A4 in 92 surgical cases with pulmonary adenocarcinoma by real-time PCR. Twelve lower E-cadherin expressing pulmonary adenocarcinomas showed a higher expression of S100A4 and a significantly poorer prognosis and enhanced venous involvement. These results suggested that reduced E-cadherin expression combined with higher S100A4 expression is related to a poorer prognosis through hematogenous metastasis in pulmonary adenocarcinoma.

E-cadherin is a factor for cell-cell adhesion and maintaining epithelial structure. The decrease or loss of E-cadherin contributed to the reduction of cell-to-cell adhesiveness, followed by the loss of cell polarity and the destruction of structures. It may induce cells to dissociate from their primary tumors and invade the surrounding tissue or metastasize to distant organs (3). The relationship of S100A4 expression with the down-regulation of E-cadherin was first reported in mouse mammary tumor cells (27). Subsequent studies further supported the evidence that there was an inverse correlation between the expression of E-cadherin and S100A4 in several human cancers; stomach, gallbladder and malignant melanoma $(7,20,28)$. Kimura et al reported that S100A4 plays a role in progression and metastasis in non-small cell lung cancer by immunohistochemistry (4). Our results revealed no inverse correlation of S100A4 and E-cadherin expression in pulmonary adenocarcinoma at the gene levels but showed that reduced E-cadherin expression combined with increased S100A4 expression was linked to a poorer prognosis in pulmonary adenocarcinoma according to real time-PCR assay.

Significant relations of S100A4 to lymph node metastasis were reported in several types of cancers, such as stomach, breast, colon and mouth $(7,18,19,29)$. Our results showed no apparent relation between S100A4 and nodal metastases in pulmonary adenocarcinoma, while adenocarcinoma with decreased E-cadherin and increased S100A4 showed no increased lymphatic invasion. The critical roles of S100A4 expression may be tumor-type dependent. S100A4 molecules may modulate the cell cycle, cell motility, cell adhesion and invasive properties (30-32). In conclusion, reduced E-cadherin expression combined with increased S100A4 expression is related to a poorer prognosis through hematogenous metastasis in pulmonary adenocarcinoma.

\section{Acknowledgements}

We thank Mr. Yuichi Tada and Dr Johbu Itoh for their technical assistance.

\section{References}

1. Takeichi M: Cadherin cell adhesion receptors as a morphogenetic regulator. Science 251: 1451-1455, 1991
2. Wheelock MJ and Jensen PJ: Regulation of keratinocyte intercellular junction organization and epidermal morphogenesis by E-cadherin. J Cell Biol 117: 415-425, 1992.

3. Hirohashi S: Inactivation of the E-cadherin-mediated cell adhesion system in human cancers. Am J Pathol 153: 333-339, 1998.

4. Kimura K, Endo Y, Yonemura Y, Heizmann CW, Schäfer BW, Watanabe $\mathrm{Y}$ and Sasaki T: Clinical significance of S100A4 and E-cadherin-related adhesion molecules in non-small cell lung cancer. Int J Oncol 16: 1125-1131, 2000.

5. Frixen UH, Behrens J, Sachs M, Eberle G, Voss B, Warda A, Löchner D and Birchmeier W: E-cadherin-mediated cell-cell adhesion prevents invasiveness of human carcinoma cells. J Cell Biol 113: 173-185, 1991.

6. Behrens J, Mareel MM, van Roy FM and Birchmeier W: Dissecting tumor cell invasion: epithelial cells acquire invasion properties after the loss of uvomorulin-mediated cell-cell adhesion. J Cell Biol 108: 2435-2447, 1989.

7. Yonemura Y, Endou Y, Kimura K, Fushida S, Bandou E, Taniguchi K, Kinoshita K, Ninomiya I, Sugiyama K, Heizmann CW, Schafer BW and Sasaki T: Inverse expression of S100A4 and E-cadherin is associated with metastatic potential in gastric cancer. Clin Cancer Res 6: 4234-4242, 2000.

8. Kohya N, Kitajima Y, Jiao W and Miyazaki K: Effects of Ecadherin transfection on gene expression of a gall bladder carcinoma cell line: repression of MTS1/S100A4 gene expression. Int J Cancer 104: 44-53, 2003.

9. Schafer BW and Heizmann CW: The S100 family of EF-hand calcium binding proteins: functions and pathology. Trends Biochem Sci 21: 134-140, 1996.

10. Watanabe Y, Kobayashi R, Ishikawa T and Hidaka H: Isolation and characterization of a calcium-binding protein derived from mRNA termed p9Ka, pEL-98, $18 \mathrm{~A} 2$, or $42 \mathrm{~A}$ by the newly synthesized vasorelaxant W-66 affinity chromatography. Arch Biochem Biophys 292: 563-569, 1992.

11. Ebralidze A, Tulchinsky E, Grigorian M, Afanasyeva A, Senin V, Revazova $\mathrm{E}$ and Lukanidin $\mathrm{E}$ : Isolation and characterization of a gene specifically expressed in different metastatic cells and whose deduced gene product has a high degree of homology to a $\mathrm{Ca}^{2+}$-binding protein family. Genes Dev 3: 1086-1093, 1989.

12. Mazzucchelli L: Protein S100A4: too long overlooked by pathologists? Am J Pathol 160: 7-13, 2002.

13. Davies BR, Davies MP, Gibbs FE, Barraclough R and Rudland PS: Induction of the metastatic phenotype by transfection of a benign rat mammary epithelial cell line with the gene for $\mathrm{p} 9 \mathrm{Ka}$, a rat calcium-binding protein, but not with the oncogene EJ-ras-1. Oncogene 8: 999-1008, 1993.

14. Grigorian M, Ambertsumian N, Lykkesfeldt AE, Bastholm L, Elling F, Georgiev G and Lukanidin E: Effect of mts1 (S100A4) expression on the progression of human breast cancer cells. Int $\mathrm{J}$ Cancer 67: 831-841, 1996.

15. Davies MPA, Rudland PS, Robertson L, Parry E, Jolicoeur P and Barraclough R: Expression of calcium binding protein S100A4 in MMTV-neu transgenic mice induces metastasis of mammary tumours. Oncogene 13: 1631-1637, 1996.

16. Lloyd BH, Platt-Higgins A, Rudland PS and Barraclough R: Human S100A4 (p9Ka) induces the metastatic phenotype upon benign tumour cells. Oncogene 17: 465-473, 1998.

17. Barraclough R: Calcium binding protein S100A4 in health and disease. Biochim Biophys Acta 1448: 190-199, 1998.

18. Gongoll S, Peters G, Mengel M, Piso P, Klempnauer J, Kreipe H and Wasielewski RV: Prognostic significance of calcium-binding protein S100A4 in colorectal cancer. Gastroenterology 123: 1478-1484, 2002.

19. Rudland PS, Platt-Higgins A, Renshaw C, West CR, Winstanley JH, Robertson L and Barraclough R: Prognostic significance of the metastasis-inducing protein S100A4 (p9Ka) in human breast cancer. Cancer Res 60: 1595-1603, 2000.

20. Nakamura T, Ajiki T, Murao S, Kamigaki T, Maeda S, Ku Y and Kuroda Y: Prognostic significance of S100A4 expression in gallbladder cancer. Int J Oncol 20: 937-941, 2002.

21. Travis WD, Corrin B, Shimosato Y and Brambilla E: in collaboration with Sobin LH and Pathologists from 14 countries. World Health Organization International Histological Classification of Tumors. Histologic typing of lung and pleural tumours. 3rd edition. Springer, Berlin, pp34-40, 1999.

22. Abe Y, Nakamura M, Ohnishi Y, Inaba M, Ueyama Y and Tamaoki N: Multidrug resistance gene (MDR1) expression in human tumor xenografts. Int J Oncol 5: 1285-1292, 1994. 
23. Abe Y, Ohnishi Y, Yoshimura M, et al: P-glycoprotein-mediated acquired multidrug resistance of human lung cancer cells in vivo. Br J Cancer 74: 1929-1934, 1996.

24. Fujimori S, Abe Y, Nishi M, et al: The subunits of glutamate cysteine ligase (GCL) enhance cisplatin resistance in human non-small cell lung cancer xenografts in vivo. Int $\mathrm{J}$ Oncol 25: 413-418, 2004.

25. Hamamoto A, Abe Y, Nishi M, et al: Aberrant expression of the gastric mucin MUC6 in human pulmonary adenocarcinoma xenografts. Int J Oncol 26: 891-896, 2005.

26. Nishi M, Abe Y, Tomii, Y, Tsukamoto H, Kijima H, Yamazaki H, Ohnishi Y, Iwasaki M, Inoue H, Ueyama Y and Nakamura M: Cell binding isoforms of vascular endothelial growth factor-A (VEGF189) contribute blood flow-distant metastasis of pulmonary adenocarcinoma. Int J Oncol 26: 1517-1524, 2005.

27. Keirsebilck AB, Bonne S, Bruyneel E, Vermassen P, Lukanidin E, Mareel M and van Roy F: E-cadherin and metastasin (mts-1/ S100A4) expression levels are inversely regulated in two tumor cell families. Cancer Res 58: 4587-4591, 1998.
28. Anderson K, Nesland JM, Holm R, Flørenes VA, Fodstad Ø and Mælandsmo GM: Expression of S100A4 combined with reduced E-cadherin expression predicts patient outcome in malignant melanoma. Mod Pathol 17: 990-997, 2004.

29. Moriyama-Kita M, Endo Y, Yoneyama Y, Heizmann CW, Schäfer BW, Sasaki T and Yamamoto E: Correlation of S100A4 expression with invasion and metastasis in oral squamous cell carcinoma. Oral Oncol 40: 496-500, 2004.

30. Takenaga A, Nakamura Y, Endo H and Sakiyama S: Involvement of S100 related calcium binding protein pEL98 (or $m t s 1$ ) in cell motility and tumor cell invasion. Jpn J Cancer Res 85: 831-839, 1994.

31. Ford HL, Salim MN, Chakravarty R, Aluiddin V and Zain SB: Expression of $m t s 1$, a metastasis-associated gene, increases motility but not invasion of a nonmetastatic mouse mammary adenocarcinoma cell line. Oncogene 11: 2067-2075, 1995.

32. Grigorian MS, Tulchinsky EM, Zain S, Ebralidze AK, Kramerov DA, Kriajevska MV, Georgiev GP and Lukanidin EM: The $m t s 1$ gene and control of tumor metastasis. Gene 135: 229-238, 1993. 